\title{
Effect of cadmium metal on barley (Hordeum vulgare) growth and development
}

\author{
Zafar Abdikulov ${ }^{1 *}$, and Marufjon Ergashev ${ }^{1}$ \\ ${ }^{1}$ Gulistan State University, 120100 Gulistan, Uzbekistan
}

\begin{abstract}
In this study, the effect of cadmium metal ion to 7, 14 and 21day after germination (DAG) autumn barley samples under laboratory condition is investigated. We determined the biomass of plant organs and the amount of cadmium accumulation in above-ground organs at germination (7 DAG), 2-leaf (14 DAG), 3-leaf (21DAG) stages. The results showed that the dry mass of 7, 14 and 21 DAG barley plant was decreased under cadmium metal treatment. However, the root biomass did not change compared with control plant. It is also observed that the 21 DAG plant accumulated around 2.4 and 5.6 times more cadmium than the 14 DAG and 7 DAG plants respectively.
\end{abstract}

\section{Introduction}

Copper $(\mathrm{Cu})$, zinc $(\mathrm{Zn})$, manganese $(\mathrm{Mn})$, and iron $(\mathrm{Fe})$ are essential heavy metals that plants require as structural and catalytic components of proteins and as cofactors of enzymes. They are commonly referred to as microelements. Nonessential heavy metals like lead $(\mathrm{Pb})$, cadmium $(\mathrm{Cd})$, mercury $(\mathrm{Hg})$, and chromium $(\mathrm{Cr})$ have no physiological function and are therefore harmful. The fact that all heavy metals are highly phytotoxic at greater doses is a common property of both essential and non-essential heavy metals [1].

Heavy metals in the environment come from a variety of natural and manmade sources. Weathering of the bedrock and volcanic activity are two natural sources. Natural concentrations of heavy metals have little effect on plants and other biota components [2]. Heavy metals have become one of the most serious anthropogenic stressors for plants and other living organisms as a result of increasing anthropogenic emissions of heavy metals from agriculture (fertilizers and pesticides), metallurgy (mining and foundry works), energy production and fuel burning, microelectronic production and waste disposal [3-7].

Cadmium is one of the toxic element for all organisms including plants [8]. Cadmium, as differences from heavy metals that is not essential for plants like other metals. However, plants can uptake this element from soil and accumulate in several vegetative organs [9]. In plants, a cadmium ion is usually accumulated as a toxic in cell and tissues. This toxicity affects structural and functional regulation, physiological processes. In results, the yield can significantly decrease [10].

Nowadays, it is know that the uptake of cadmium carry out through ion transport system, same as other micro elements. It is mentioned that the accumulation speed of this metal in plant organs depends to its growth condition and biological species [11-14].

Some researches indicate accumulation of cadmium changes during the oncogenes in plants. But all experimental data is similar, the references are not enough on that issue.

In this study, we aimed to investigate the accumulation of cadmium ion in above-bottom organs in barley plant.

\section{Materials and Methods}

In our experiment, we used one of autumn barley cultivar, called Mavlono. The selected Mavlono cultivar seeds were sown to soil-filled special containers. The Knop solution was used as nutrition for barley growth. As an effect of cadmium, we have added $100 \mathrm{mM}$ cadmium sulphate $\left(\mathrm{CdSO}_{4}\right)$ for four days. During the experiments, we studied a barley cultivar at the germination (7 DAG), 2 leaf (14 DAG) and 3 leaf (21DAG) developmental stages. We measured the amount of Cadmium from above-bottom organs included root, shoot, leaf plastics. The amount of cadmium was determined in the polygraph using an inversion method on a voltampermeter $[10,15]$.

\footnotetext{
${ }^{*}$ Corresponding author: abdikulov.zafar2017@yandex.ru
} 


\section{Results and Discussion}

In this research, Mavlono cultivar of barley was grown at Laboratory condition and treated with relevant solution of $\mathrm{CdSO}_{4}$ for evaluation of some physiological processes. An amount of accumulation of Cadmium was determined in above-bottom plant organs at 7 DAG (days after germination), 14 DAG and 21 DAG stages. Our results showed that a similar effect of cadmium at 7.14 and 21 DAG was obtained. In this tablel described that dry mass of barley was decreased in metal treatment at all stages. However, the root biomass was followed with control. The same reaction of barley to cadmium has been observed by other authors using similar or higher concentrations of this metal [16].

Table 1. Effect of cadmium metal ions in above-ground biomass in barley

\begin{tabular}{|l|l|l|l|l|}
\hline \multirow{2}{*}{ Samples } & \multicolumn{2}{|c|}{ Shoot dry mass, mg } & \multicolumn{2}{c|}{ Root dry mass, mg } \\
\cline { 2 - 5 } & Control & Treatment & Control & Treatment \\
\hline 7 DAG & $167.8 \pm 4.5$ & $134.9 \pm 4.8^{*}(80)$ & $154.7 \pm 13.2$ & $141.9 \pm 7.5(92)$ \\
\hline 14 DAG & $254.9 \pm 16.1$ & $182.9 \pm 4.0^{*}(72$ & $268.9 \pm 24.4$ & $246.5 \pm 16.7(92)$ \\
\hline 21 DAG & $393.5 \pm 15.7$ & $325.8 \pm 12.8^{*}(83)$ & $273.0 \pm 21.8$ & $325.1 \pm 24.6(119)$ \\
\hline
\end{tabular}

There is no effect of cadmium on the root biomass because it has a sufficiently developed root system before starting the experiment. Chemical analysis of plants in the control variant showed that the cadmium content was $0.19-0.26$ $\mathrm{mg} / \mathrm{g}$ in the roots. However, it was not found cadmium in above organs.

Table 2 shows that the amount of cadmium significantly increased in plant root after treated by cadmium sulphate solution. It was also found that the amount of cadmium varies in the root of plants under different stages.

Table 2. Amount of accumulated cadmium metal ion in above-ground organs in barley

\begin{tabular}{|l|l|l|l|l|l|}
\hline \multirow{2}{*}{ Samples } & \multicolumn{5}{|c|}{ Amount of cadmium, mg/g } \\
\cline { 2 - 6 } & root & shoot & 1-leaf & 2-leaf & 3-leaf \\
\hline 7 DAG & $16.19 \pm 0.48$ & $3.41 \pm 0.09$ & $3.02 \pm 0.12$ & & \\
\hline 14 DAG & $23.89 \pm 0.46^{*}$ & $6.02 \pm 0.10^{*}$ & $0.66 \pm 0.01^{*}$ & $1.73 \pm 0.08$ & \\
\hline 21 DAG & $42.80 \pm 1.41^{*}$ & $7.59 \pm 0.16^{*}$ & $1.22 \pm 0.05^{*}$ & $0.70 \pm 0.03^{*}$ & $1.45 \pm 0.03$ \\
\hline
\end{tabular}

Amount of cadmium at 21 DAG was 1.8 times higher than 14 DAG and 2.6 times higher than 7 DAG when the plants treated with metal for four days. A similar result was obtained with other researches. Accumulation of zinc in maize and other works can be example in this field.

Analyzing of above organs shows, amount of cadmium increased in shoot and root under growth stages. Meantime, it is also determined that amount of cadmium did not change or slightly decreased in leaves. Accumulation of cadmium in plant organs showed that the 21DAG plant accumulated 2.4 times more cadmium than the 14DAG plant and 5.6 times more than the 7DAG plant.

However, it was found that the amount of cadmium in the roots and stems significantly increased by follwed plant ages, while the total amount of cadmium in the leaves has not changed although it's number is increased.

We have found that as the barley plant developmental stage may positively correlates with the metal accumulation ability of plant roots.

It is also known that the rate of absorption or accumulation of minerals may depends to the plant development stages.

The uptake of mineral element nutrition has been stimulated during the first week of vegetation period in annual cereal plants.

In case, it is facilitated by the structural-functional alterations where occurs in root system. In particular, there is a significant increases in root surface area for absorption during this period. It is also increases on the cation exchange capacity of cell membranes, the hydraulic variability and changes the working intensity of ion transport systems.

The uptake of toxic ions into the roots carried out by the same mechanisms with the regular ions, therefore, absorption of cadmium into the roots also raise in barley plant.

Plant developmental stages greatly influence to increase of cadmium absorption in root and shoot, but decrease in the leaves. Such process may be related to the speed and properties of the metal ion movements through the organs. For example, in experiments with rice, cadmium ions were found one hour after the onset of treatment in the shoot. In case, the movement of cadmium ions may blocked by many anion groups in the xylem [17].

The cadmium distribution was significantly decreased in 14 and 21DAG compared to 7DAG plant samples in above organs. This indicates, there is a barrier function in root system. Such as distribution of cadmium has been observed in the Vigna radiation plant. 
It is known the metal resistance depends on the effectiveness of mechanisms that provide immobilization of metal ions in the plant root, which allowed protecting the negative effects from above organs. Such mechanisms have included ion binding in root cell apoplasts, chelating in the cytoplasm, and compartmentalization in vacuoles $[9,18]$. Moreover, the xylem controls the transport of metal ions in above organs by altering of transport proteins activity [19]. However, there is other evidence that the cadmium movement from above to bottom organs is decreased via phloem tissue. But there are no clear references on the mechanisms for comparison of developmental stages.

It can be assumed that the factors related developmental phases may lead to increased immobilization of cadmium ions in the root.

In root cells, there may be differences in the effectiveness of the metal binding mechanisms depending on the phases of plant. For instance, after treated of cadmium solution for barley plant, the amount of phytochelatin (kind of peptides involved in the binding of heavy metal ions in the cytoplasm) in root cells can be significantly increased compared to young autumn barley plant samples. Recent data suggest that the barrier function of the roots also increases during the plant developmental stages.

\section{Conclusions}

Our studies showed that the effect of cadmium ion remained at the same level, although a significant differences were observed at the amounts of metal ions in 7, 14 and 21 DAG plants.

It was also observed that the amount of cadmium has increased in root and shoot, but decreased in leaves under developmental stages of barley.

It was found that the transfer of cadmium metal was reduced from roots to shoot under the developmental stages. This may be due to age-related changes in stem cells and tissues, and an increase in the efficiency of the mechanisms that ensure the immobilization of excess metal ions in its underground organs. This condition allows in above organs, especially protect the leaves from toxicity of cadmium. In case, plant root may easily adapt to the increase of metal concentration.

\section{References}

1. S. K. Panda, S. Choudhury, Chromium stress in plant, Brazilian Journal of Plant Physiology 17, 95-102 (2005)

2. A. Schutzendubel, A. Polle, Plant responses to abiotic stress: heavy metal-induced oxidative stress and protection by mycorrhization, Journal of Experimental Botany 53, 1351-1365 (2001)

3. Seregin I.V., Ivanov V. B. Physiological aspects of Cadmium and Lead toxic effects on higher plants, Russian Journal of Plant Physiology 48(4), 523-544 (2001)

4. E. I. Ugwu, O. Tursunov, D. Kodirov, L. M. Shaker, A. A. Al-Amiery, I. Yangibaeva, F. Shavkarov, Adsorption mechanisms for heavy metal removal using low cost adsorbents: A review, IOP Conf. Ser.: Earth Environ. Sci. 614, 012166 (2020)

5. J. W. Dobrowolski, O. Tursunov, O. Pirimov, O. J. Nazarova, Laser Biotechnology for Nutritional Health, Sustainable Environment and Development, IOP Conf. Ser.: Earth Environ. Sci. 614, 012108 (2020)

6. N. Toshpulatov, O. Tursunov, D. Kodirov, G. Kholmuratova, Environmentally friendly technology for the destruction of tobacco mosaic viruses (TMV) from selected species of plants, IOP Conf. Ser.: Earth Environ. Sci. 614, 012133 (2020)

7. J. W. Dobrowolski, D. Bedla, T. Czech, F. Gambus, K. Gorecka, W. Kiszcak, T. Kuzniar, R. Mazur, A. Nowak, M. Sliwka, O. Tursunov, A. Wagner, J. Wieczorek, M. Swiatek, Integrated Innovative Biotechnology for Optimization of Environmental Bioprocesses and a Green Economy, Optimization and Applicability of Bioprocesses, eds H. Purohit, V. Kalia, A. Vaidya, A. Khardenavis, Springer, Singapore, chapter 3 pp. 27-71 (2017)

8. G. J. Wagner, Accumulation of cadmium in crop plants and consequences to human health, Advances in Agronomy 51, 173-212 (1993)

9. J. A. C. Verkleij, A. Goldhirsh, D. M. Antosiewisz, Dualities in plant tolerance to pollutants and their uptake and translocation to upper plant parts, Environ. Exp. Bot. 67, 10-22 (2009)

10. A. F. Titov, B. B. Talanova, H. M. Kaznina, G. F. Lay Dinen, Plant resistance to heavy metals, Karel Scientific Center RAS, Petrozavodsk (2007)

11. A.Wahid, M. Arshad, M. Farooq, Cadmium phytotoxicity: responses, mechanisms and mitigation strategies, Organic farming, pest control and remediation of soil pollutants, Ed. E. Lichtfouse, Springer, pp. 371-403 (2009)

12. D. I. Bashmakov, A. S. Lukatkin, Ecological and physiological aspects of the accumulation and distribution of heavy metals in higher plants, Mordov Un-Ta Publisher, Saransk (2009)

13. Z. Hassan, M. G. M. Aarts, Opportunities and feasibilities for biotechnological improvement of Zn, Cd, or Ni tolerance and accumulation in plants, Environ. Exp. Bot. 72, 53-63 (2011) 
14. M. Regvar, V. K. Mikuš, Recent advances in understanding of plant responses to excess metals: exposure, accumulation and tolerance, Sulfur assimilation and abiotic stress in plants, Ed. N. A. Khan, Springer, Berlin, pp. $227-251(2008)$

15. Yu. V. Batova, A. F. Titov, N. M. Kaznina, G. F. Laydening, Accumulation of cadmium and its distribution in organs in barley plants of different ages, Works of Kerelskiy Scientific Center RAS 2, 32-37 (2012)

16. M. A. P. Mejía, B. R. Díez, M. F. Pascual, Effect of cadmium ion excess over cell structure and functioning of Zea maysand Hordeum vulgare, Biochemical Systematics and Ecology 38, 285-291 (2010)

17. S. Fujimaki, N. Suzui, N. S. Ishioka, Traising cadmium from culture to spiklet: noninvasive and quantitative characterization of absorption, transport and accumulation of cadmium in an intact rice plant, Plant Physiology 152, 1796-1806 (2010)

18. A. Lux, M. Martinka, M. Vaculik, P. J. White, Root responses to cadmium in the rizosphere: a review, Journal of Experimental Botany 62, 21-37 (2011)

19. L. Van der Vliet, C. Peterson, B. Hale, Cd accumulation in roots and shoots of durum wheat: the roles of transpiration rate and apoplastic bypass, Journal of Experimental Botany 58, 2939-2947 (2007) 